\title{
Discutindo gênero na escola: um relato de experiência
}

\author{
Augusto José Bezerra de Andrade \\ Universidade do Estado do Rio Grande do Norte - UERN, Brasil \\ Erika Carla de Sousa Dias \\ Universidade do Estado do Rio Grande do Norte - UERN, Brasil \\ Rafael Tavares Silveira Silva \\ Universidade do Estado do Rio Grande do Norte - UERN, Brasil \\ Ellany Gurgel Cosme do Nascimento \\ Universidade do Estado do Rio Grande do Norte - UERN, Brasil
}

\begin{abstract}
RESUMO
Trata-se de um relato de experiência vivenciado pelos discentes da disciplina Estágio Curricular Supervisionado II, do Curso de Enfermagem da Universidade do Estado do Rio Grande do Norte (UERN), Campus Avançado Prof. ${ }^{a}$ Maria Elisa de Albuquerque Maia (CAMEAM) da cidade de Pau dos Ferros-RN. O relato teve como tema os papéis de gênero (masculino e feminino), realizado no primeiro semestre de 2017, com alunos da Escola Estadual Prof. a Maria Edilma de Freitas em Pau dos Ferros-RN. Os escolares se envolveram nas atividades, demonstrando aproximação com a discussão. Observou-se que alguns refletiram sobre as discussões, mudando as concepções que expressavam a respeito dos papéis de gênero e adotando um discurso igualitário. Implementar foi relevante e contribuiu para a formação e desenvolvimento da prática docente no Ensino Fundamental.
\end{abstract}

PALAVRAS-CHAVE: Educação Popular em Saúde. Escolares. Gênero. Enfermagem.

\section{DISCUSSING GENDER IN SCHOOL: A REPORT OF EXPERIENCE}

\begin{abstract}
It is an experience reported by the students of the discipline Curricular Supervised Internship II, of the Nursing Course of the State University of Rio Grande do Norte (UERN), Advanced Campus Prof. Maria Elisa de Albuquerque Maia (CAMEAM) of the city of Pau dos Ferros-RN. The report had with theme Gender Roles (Male and Female), realized in the first semester of 2017, with students from the State School Prof. Maria Edilma de Freitas in Pau dos Ferros-RN. The schoolchildren got involved in the activity, demonstrating an approximation with the discussion. It was observed that some of them reflected about the discussions, changing the conceptions they expressed about of the gender roles, adopting an egalitarian discourse. Implementing was relevant and contributed to the training and development the teaching practice in elementary education.
\end{abstract}

KEY WORDS: Popular Health Education. Schoolchildren. Genre. Nursing. 


\section{DISCUTINANDO GÉNERO EN LA ESCUELA: UN RELATO DE EXPERIENCIA}

\section{RESUMEN}

Se trata de un relato de experiencia vivido por los discentes de la disciplina Etapa Curricular Supervisionado II, del Curso de Enfermería de la Universidade do Estado do Rio Grande do Norte (UERN), Campus Avançado Prof ${ }^{a}$ Maria Elisa de Albuquerque Maia (CAMEAM) de la ciudad de Pau dos Ferros-RN. El relato tuvo como tema los Papeles de género (Masculino y Femenino), realizado en el primer semestre de 2017, con alumnos de la Escuela Estadual Prof ${ }^{a}$ Maria Edilma de Freitas em Pau dos Ferros-RN. Los escolares se involucraron en las actividades, demostrando acercamiento con la discusión. Se observó que algunos reflexionaron sobre las discusiones, cambiando las concepciones que expresaban acerca de los roles de género, y adoptando un discurso igualitario. Implementar fue relevante, y contribuyó a la formación y desarrollo de la práctica docente en la enseñanza fundamental.

PALABRAS CLAVE: Educación Popular en Salud. Escolares. Género. Enfermería.

\section{INTRODUÇÃO}

A Educação Popular em Saúde (EPS) possibilita a promoção da saúde, uma vez que estimula o senso crítico e a liberdade das pessoas para cuidarem de si mesmas, refletindo em escolhas conscientes. A criação do vínculo e o diálogo entre comunidade e profissionais de Saúde, além da valorização do conhecimento popular, são condições fundamentais para a efetivação desse protagonismo (COSTA; SILVA; DINIZ, 2008). A Promoção da Saúde se concretiza com o objetivo de romper com a excessiva fragmentação na abordagem do processo saúde-adoecimento e reduzir a vulnerabilidade, os riscos e os danos que nele se produzem (EVANGELISTA et al., 2016).

A I Conferência Internacional sobre a Promoção da Saúde, em 1986, teve como principal resultado a divulgação da Carta de Ottawa, que define Promoção da Saúde como “o processo de capacitação da comunidade para atuar na melhoria da sua qualidade de vida e saúde, incluindo uma maior participação neste processo" (1986). A atenção à saúde modificou-se com o decorrer do tempo, trazendo a necessidade de os profissionais da saúde e da população reivindicarem por diversos direitos, principalmente os relacionados à saúde (PIOVESAN et al., 2016).

Diante das reivindicações e debates, o sistema de saúde se modificou e, consequentemente, sua concepção também, deixando de ser vista como ausência de doença, para ampliar suas práticas de atuação, como a promoção e a prevenção, sem obviamente excluir a recuperação da saúde. O termo promoção é derivado do vocábulo latino promotio, que é atribuído à melhoria das condições de algo e às atividades com a intenção de dar a conhecer algo. No âmbito da saúde coletiva, as ações de Promoção de Saúde estão focadas na educação 
em saúde, com adoção de mudanças de estilo de vida, aconselhamentos, estimulando práticas coletivas que visem à saúde da comunidade (CÉSAR et al., 2016).

O modelo tradicional de Educação em Saúde compreendia saúde como ausência de doença, utilizando estratégias educativas orientadas por pressupostos biomédicos. As metodologias de ensino e aprendizagem conservadoras/tradicionais são, historicamente, fragmentadas e reducionistas. Esta prática pedagógica se baseia na concepção de educação como ato de depositar, transferir e reproduzir valores e conhecimentos para seres passivos, ingênuos e desprovidos de poder, denominada por Paulo Freire de "educação bancária", que cultivava o entendimento equivocado de educação como mero "depósito de conhecimento dentro da inteligência silenciada do educador, o que representa um obstáculo para a promoção da saúde eficaz e que atenda às demandas sociais (MONTEIRO, 2015; ALVES; ALVES; ASSIS, 2016).

A Reforma Sanitária ${ }^{1}$ rompe com esses valores, propondo uma nova aproximação da população e de seu saber, comprometendo-se com a transformação social. Entretanto, no cotidiano dos serviços de saúde, as relações hierarquizadas entre os profissionais de saúde e o lugar do incontestável saber biomédico interpõem-se às tentativas de construção de novas práticas de educação e saúde. Assim, pelos Movimentos Sociais surge a EPS, que contribui, por meio de metodologias e saberes, para a constituição de novos sentidos e práticas no âmbito do setor saúde, assumindo um papel imprescindível para o empoderamento dos sujeitos sobre sua saúde, compreendida em seu sentido amplo (BORNSTEIN et al., 2015; BRASIL et al., 2017).

Destarte a EPS é uma prática pedagógica que visa desenvolver a tomada de consciência, contribuindo para a transição da consciência ingênua para a consciência crítica. Paulo Freire, que foi o grande fundamentador da educação popular, defendia que não existe um método prescritivo a ser seguido, mas sim certos princípios direcionadores, entre os quais: saber ouvir, desmontar a visão mágica, aprender/estar com o outro, assumir a ingenuidade dos educandos e viver pacientemente impaciente. A Educação Popular é um modo comprometido e participativo de conduzir o educando orientado pela perspectiva de realização de todos os direitos do povo, incluindo A Promoção da Saúde (KRUSCHEWSKY; KRUSCHEWSKY; CARDOSO, 2016; ALVES; ALVES; ASSIS, 2016).

\footnotetext{
${ }^{1}$ Nos anos 70, no Brasil, surgiu um movimento postulando a democratização da saúde, justamente em um período no qual novos sujeitos sociais emergiram nas lutas contra a ditadura. Essa luta ficou conhecida como Movimento da Reforma Sanitária Brasileira (MRSB), constituindo-se em amplas mobilizações da sociedade pela redemocratização. Expressou a indignação frente às aviltantes desigualdades e à mercantilização da saúde. Configurou-se como ação política em torno de um projeto civilizatório de sociedade inclusiva, solidária, tendo a saúde como direito universal de cidadania (SOUTO; OLIVEIRA, 2016).
} 
Em âmbito nacional, a Política Nacional de Promoção da Saúde (PNPS) afirma que as ações voltadas à Promoção da Saúde têm como objeto os problemas e as necessidades de saúde da população com foco em seus determinantes, com atuação diretamente nos efeitos do adoecer, mas também abrangendo as comunidades e outros setores. Indicando, também, que a Promoção da Saúde incide sobre as condições de vida da população e favorece a ampliação de escolhas saudáveis por parte dos sujeitos e da coletividade no território onde vivem (BRASIL, 2006).

Neste contexto, o ambiente escolar assume um papel fundamental, pois é nele que se re/constrói ou se perpetua uma ideologia através da problematização de valores e crenças, além de ser este, um cenário propício para o desenvolvimento de ações educativas em saúde. É a juventude o momento decisivo para a construção e solidificação dos hábitos e atitudes e, em vista disso, a importância do papel da escola como meio potencializador para o desenvolvimento de um trabalho direcionado, sistematizado e permanente (MONT'ALVERNE; CATRIB, 2013).

A escola, portanto, se configura como um espaço privilegiado de articulação entre os conteúdos científicos e a vida de cada um, sendo assim, de fundamental importância no processo saúde/doença dos escolares. Deve-se visualizá-la como um espaço de promoção da saúde, pois congrega crianças e adolescentes (GUIMARÃES; AERTS; CÂMARA, 2012).

Um instrumento de fortalecimento e efetivação da Promoção de Saúde é a articulação entre a educação escolar e o EPS, o que é viável através do Programa Saúde na Escola (PSE), pois quando há articulação entre os serviços de saúde, a comunidade e escola, além do próprio sujeito, viabiliza o bem-estar e a qualidade de vida dos envolvidos (COSTA; SILVA; DINIZ, 2008). A proposta do PSE, portanto, é uma oportunidade para estabelecer e manter um vínculo pautado na co-responsabilização, o que permite, aos profissionais de saúde, a percepção do seu papel social como educador, estreitando os laços com os jovens. Para os educadores, permite enxergar o seu papel na prevenção de doenças e na promoção da saúde dos escolares. Dessa forma, a aproximação entre escola e unidade de saúde contribui para ajudar os adolescentes a transformarem a informação científica em comportamentos saudáveis (SANTIAGO et al., 2012).

A escola se configura como um espaço social no qual o sujeito passa parte de sua vida, sendo um dos principais ambientes promotor de contatos interpessoais, logo, deve colaborar para o crescimento de uma educação que supere as imposições de identidade de gênero e orientação sexual que são observadas nas várias formas de relacionamentos e desenvolvimento enquanto sujeito (LEÃO, 2009; NETO, 2015).

O termo gênero, por ser polissêmico, é muitas vezes confundido com o termo sexo, constantemente sendo-lhes atribuído o mesmo significado. Porém, o termo sexo deve se 
associar a questões biológicas dos indivíduos e o termo gênero deve ser encarado, segundo Rabelo (2010, p. 161) como

Uma construção social de atributos diferentes a homens e mulheres consolidada durante toda a vida, o que determina as relações entre os sexos em vários aspectos. $\mathrm{O}$ uso deste termo objetiva sublinhar o carácter social das distinções fundadas sobre o sexo e a rejeição do uso da palavra sexo que, etimologicamente, se refere à condição orgânica que distingue o macho da fêmea, enquanto que a palavra gênero se refere ao código de conduta que rege a organização social das relações entre homens e mulheres.

A desigualdade de gênero aponta que mulheres e homens não têm as mesmas oportunidades e resultados na vida em sociedade nos vários âmbitos (educação, saúde, trabalho e emprego, família, entre outros), em resultado das relações sociais de gênero que estruturam e condicionam a vida de todos. É possível, então, encarar o termo gênero para se referir ao caráter socialmente construído das diferenças entre homens e mulheres, recusando, dessa forma, as explicações naturalizadoras e essencialistas para a desigualdade. Fatores histórico-culturais da sociedade que, ao determinarem uma construção social de papéis e atributos de gênero em função do sexo biológico, conduzem a uma concepção do masculino e do feminino diferenciada e hierarquizada em termos de importância (MONTEIRO; AGOSTINHO; DANIEL, 2015).

Há uma grande dificuldade, por parte dos professores, em refletir sobre as questões de gênero. $O$ conceito de gênero a partir da concepção de que a masculinidade e a feminilidade são construções culturais ainda é uma compreensão que parece distante da realidade escolar. Pensar sobre questões de gênero de forma mais contemplativa torna-se uma tarefa complicada para os profissionais da educação (MADUREIRA; BRANCO, 2015).

Criam-se diversas representações sociais sobre os atributos e características pessoais, competências, interesses e motivações dos homens e das mulheres, no âmbito do trabalho e da família, que reverberam em práticas sociais coerentes com essas representações. Assim, tradicionalmente, atribui-se ao homem papéis e responsabilidades no domínio público, de sustento, e de orientação para resultados, de competitividade e força, e à mulher papéis no domínio privado, de cuidado, com base em características mais emocionais e relacionais (MONTEIRO; AGOSTINHO; DANIEL, 2015; PRATES; MARCHÃO, 2015).

Dessa forma, fez-se necessária uma atividade de intervenção por parte dos discentes do $7^{\circ}$ período do Curso de Enfermagem da Universidade do Estado do Rio Grande do Norte (UERN), Campus Avançado Prof. ${ }^{\text {a }}$ Maria Elisa de Albuquerque Maia (CAMEAM) localizada na cidade de Pau dos Ferros-RN, a qual foi realizada com os escolares do $6^{\circ}$ ano do Ensino Fundamental da Escola Estadual Prof. ${ }^{a}$ Maria Edilma de Freitas. 
A implementação tinha como tema os Papéis de Gênero e, como intuito, o de contribuir para que os escolares se tornassem multiplicadores e disseminadores de um pensamento de igualdade nas relações de gênero, de modo que essas discussões possibilitassem uma melhor compreensão da influência dos papéis de gênero como determinante do processo saúde/doença dos sujeitos e comunidade.

Desse modo, o objetivo deste artigo é relatar a experiência de EPS na escola, vivida pelos acadêmicos de enfermagem, trazendo as principais impressões e inquietações no transcorrer da atividade e as contribuições para a formação profissional e a prática docente.

\section{CAMINHOS METODOLÓGICOS}

Trata-se de um relato de experiência vivenciado pelos discentes da disciplina Estágio Curricular Supervisionado II, do Curso de Enfermagem da Universidade do Estado do Rio Grande do Norte (UERN), Campus Avançado Prof. ${ }^{a}$ Maria Elisa de Albuquerque Maia (CAMEAM) da cidade de Pau dos Ferros-RN.

A vivência ocorreu no primeiro semestre de 2017 na Escola Estadual Professora Maria Edilma de Freitas, situada no Princesinha do Oeste, um bairro classe média da cidade de Pau dos Ferros/RN, entretanto com alunado de baixa renda. Ela possui 25 turmas distribuídas em: 09 no turno matutino, 07 no vespertino e 09 no noturno. A média de alunos é de 35 por turma no Fundamental, sendo 10 salas de aula. No Ensino Médio, são 40 alunos por turma, distribuídos em 06 salas. No Ensino Médio Diferenciado, são 03 salas e, na Educação de Jovens e Adultos (EJA), são 06. Com relação à média da faixa etária, o $6^{\circ}$ Ano-A é constituído por alunos com 12 anos e o $6^{\circ}$ Ano-B por discentes com 13 anos. No Ensino Médio, até 18 anos e, na EJA, maiores de 18 anos.

Partindo da premissa de que é necessário conhecer a realidade antes de implementar as ações por meio de EPS, os discentes foram designados a ir na Escola Estadual Prof. ${ }^{a}$ Maria Edilma de Freitas com o objetivo de conhecer como ocorre sua dinâmica e organização, bem como, as necessidades de seus alunos. Nesta fase, conversou-se com o diretor/coordenação, professores e alunos, para levantamento de informações e problemáticas que subsidiaram o planejamento das intervenções. Os professores mostraram a realidade existente no tocante às necessidades de intervenções em sala de aula. Relataram o perfil de cada turma, ficando evidenciado que prevalece alunos "desinteressados, rebeldes e barulhentos".

Dentre as temáticas sugeridas, os professores referiram: sexualidade: infecções sexualmente transmissíveis, gravidez na adolescência, violência sexual, planejamento familiar, problemas psicológicos e "bullying”. Coordenação: alimentação, sexualidade, drogas, questões 
emergentes: dengue e febre e amarela. Alunos: conflitos psicológicos, educação sexual, ansiedade, lixo, água e febre amarela.

A partir do contato inicial com a escola, realizou-se a apresentação para os professores de Estágio Curricular Supervisionado II das problemáticas levantadas e posteriormente elencamos quais temáticas iríamos planejar as implementações. E assim, foi designado a elaboração de um relatório em que constasse estratégias metodológicas que subsidiariam a aplicabilidade da implementação. Após o relatório, houve novamente um momento de apreciação dos professores do componente curricular supracitado acerca do planejamento e ideias, na ocasião foram feitas críticas e sugestões no que deveria melhorar nas estratégias já definidas.

A implementação ocorreu em duas etapas, organizadas por meio de oficinas; no primeiro momento, realizou-se uma dinâmica que tinha como título "A viagem"; na sequência houve a dinâmica "A quem pertence?" e, por fim, o momento avaliativo denominado "A igualdade de gênero" por meio de perguntas e respostas. Elaborou-se uma produção técnica em forma de jornal que foi entregue aos discentes e exposto no mural da escola.

\section{DESCRIÇÃO DA VIVÊNCIA}

A atividade educativa foi realizada na Escola Estadual Prof. ${ }^{\text {a }}$ Maria Edilma de Freitas na turma $6^{\circ}$ ano-A do Ensino Fundamental, em 23 de março de 2017 iniciando às 07 horas e 30min, com o intuito de discutir, a partir dos conhecimentos prévios dos estudantes, seus conceitos e suas concepções a respeito dos papéis de gênero. Dentro de aproximadamente 50 minutos, procurou-se envolver o público ao máximo possível nos debates e sempre tomando como ponto de partida o saber que já possuíam.

Inicialmente houve a apresentação dos graduandos e dos escolares por meio da dinâmica "A viagem", na qual foi solicitado que cada um dissesse o seu nome e o de um objeto que levaria para uma viagem com a inicial de seu nome. Foi um momento proveitoso e de diversão que proporcionou uma aproximação entre ambos e possibilitou a observação das primeiras impressões a respeito da turma, notando-se que se tratava de um público participativo, porém inquieto; em seguida, houve a explicação do motivo da implementação da atividade e como a mesma se processaria.

Na sequência, foi realizada uma dinâmica de aproximação e discussão denominada “A quem pertence?", na qual foram levados alguns objetos (bola, bonecas, carrinho, maquiagem, super-heróis, princesas, tênis, panelas, ferramentas), que culturalmente são 
estereótipos de homem ou de mulher, para que assim os escolares pudessem distribuí-los em três lugares específicos codificados como: homem, mulher e ambos.

Todos os escolares se envolveram na atividade e demonstraram já ter aproximação com a discussão. Houve, de início, uma certa discordância acerca de onde encaixar alguns objetos, de forma que foi possível ver que alguns dos participantes ainda seguiam os conceitos disseminados pela sociedade, mas ao mesmo tempo foi possível observar que alguns tinham uma visão que ultrapassava esses conceitos preestabelecidos, já que conseguiam dissociar os objetos da exclusividade de pertencerem a um determinado gênero, fato visto no momento em que objetos como ferramentas e panelas que são fortemente representações de masculinidade e feminilidade, respectivamente, foram colocados no local determinado com sendo para ambos.

No momento da atividade, percebeu-se que os escolares ainda denominavam alguns objetos apenas para mulheres, como por exemplo o uso de maquiagem, e super-heróis para homens, gerando discussão entre os mesmos, surgindo até um certo espanto quando alguns objetos eram colocados no local destinado para ambos, ou quando era colocado no local do sexo oposto ao visto como normal na sociedade.

Assim, viu-se que os participantes tinham opiniões formadas a partir de seus cotidianos, de forma que trouxeram relatos de exemplos para justificar o porquê de onde escolheram colocar os objetos, como em casos em que alguns afirmaram conhecer mulheres que trabalham como mecânicas e acharem normal as mesmas utilizarem ferramentas, como também aceitarem homens cozinharem. Porém, no que se refere ao uso de maquiagem ainda há uma certa surpresa e espanto referente a homens realizarem tal prática. De modo geral, ficou evidente que era um assunto presente no universo dos escolares e que os mesmos conseguiam enxergar a sua presença em suas vidas e como tal afetaria seu posicionamento e maneira de ser diante a sociedade.

Após os momentos de aproximação e discussão, houve a avaliação dos conhecimentos construídos. Utilizou-se uma estratégia metodológica a qual tinha como título "A igualdade de gênero". A turma foi dividida em 05 grupos e cada um escolheu o seu relator. Após essa divisão, cada grupo recebeu uma pergunta e teve 05 minutos para refletir acerca da indagação e a seguir, o relator expôs sua conclusão para o grande grupo. As perguntas utilizadas foram: De quem é a responsabilidade de cuidar da casa e da família? As tarefas dos homens são diferentes das tarefas das mulheres? Por quê? Há algum problema em um homem se relacionar com mais de uma mulher e a mulher se relacionar com mais de um homem? Há diferença das profissões/empregos de homem para mulher? Meninos e meninas podem brincar da mesma brincadeira?

Foi um momento de reconstrução de conceitos de modo que expressaram suas opiniões 
e ainda enfatizaram que mudariam novamente de locais os objetos utilizados para a dinâmica anterior. Esse momento possibilitou observar que alguns escolares refletiram sobre as discussões, despertando mudanças nas concepções que expressavam sobre os determinantes dos papéis de gênero adotando um discurso de igualdade.

A escola, no que tange aos profissionais e aos alunos, mostrou-se receptiva, disponível e colaborativa. Dentre os pontos positivos da implementação, cabe destaque a participação dos alunos, a interação que conseguimos desenvolver com eles. Por ter sido a primeira vez que desenvolvemos práticas por meio EPS com escolares do Ensino Fundamental, foi desafiador, pois, no decorrer da atividade, desenvolvemos habilidades de como trabalhar com alunos, considerando as peculiaridades de cada um. Evidenciou-se, como ponto negativo na captação, que a referida instituição não é atendida de maneira eficaz pelo PSE.

Considerando os objetivos propostos para a intervenção, estes foram alcançados, tendo ocorrido a efetiva participação dos escolares, de modo que o planejamento proposto foi desenvolvido de maneira satisfatória, possibilitando uma troca mútua de saberes em que todos os envolvidos expressaram suas opiniões, partindo realmente do saber popular e trazendo-os para serem os protagonistas da ação.

Vale salientar que foi elaborada uma produção técnica em forma de jornal, "Jovens News", o qual tinha como proposta trazer alguns exemplos por meio de notícias sobre famosas que exercem profissões que culturalmente são taxadas como do sexo oposto. O objetivo era trazer a realidade vivenciada por famosos e promover a problematização diante das dificuldades expressadas por eles nos noticiários. Ao final, alguns jornais foram expostos nos corredores da escola para que outras pessoas também pudessem conhecer a discussão.

\section{DISCUSSÃO}

$\mathrm{Na}$ dinâmica de aproximação e discussão, foi possível perceber a influência da sociedade na construção dos Papéis de Gênero, através dos relatos dos escolares. A maioria das sociedades reproduz uma divisão desses papéis com base em padrões masculinos e femininos, constituída em torno da separação da vida social pública (política e mercado de trabalho) associada ao homem e a vida privada (cuidados domésticos e da família) para a mulher (AQUINO, 1998).

Reconhece-se que a escola não está neutra nessa discussão, ela influencia a construção da identidade de gênero e, ao abordar essas questões, reflete sobre relações das práticas educacionais cotidianas, desconstruindo e redescobrindo conceitos (FINCO, 2003). Se os 
conhecimentos desenvolvidos forem integradores e igualmente valorizarem as representações de gênero, os seus saberes e as suas construções, bem como, o modo como se articulam as relações entre eles e no interior de cada um, esse conhecimento torna-se mais abrangente, mais próximo da realidade e mais integrador da diversidade de identidades, sendo uma condição essencial para que todos os sujeitos se revejam nas inúmeras possibilidades de futuro e incorporem o mesmo direito à escolha tanto no âmbito pessoal como profissional (ALVAREZ; VIEIRA, 2014).

A existência das diferenças de gênero masculino e feminino dentro da sociedade é bem perceptível e de difícil desconstrução. Entretanto, o que muitas vezes parece prevalecer é a ideia de que a divisão entre o feminino e o masculino seria algo natural como se já fosse prédeterminado, mas não é, e deve ser entendido como uma construção histórica. Assim, faz-se necessário despir-se de conceitos culturalmente estabelecidos visando uma igualdade de gênero e a superação da visão estereotipada que circunda os sujeitos (MILHOMEM, 2015).

Trabalhar a discussão dos Papéis de Gênero dentro da Educação possibilita e fortalece a construção social de sujeitos emancipados e que, por meio do empoderamento, advindo do conhecimento a respeito do tema, possam construir-se enquanto sujeitos livres de estereótipos. Deve-se lutar para que a escola se torne mais do que um lugar de reprodução dos ideais conservadores postos na sociedade, devemos buscar utilizar o seu espaço em favor da construção de uma Educação que contemple as várias dimensões da vida social (MELO, 2014).

Desse modo, o PSE se configura como uma possibilidade de superar uma necessidade há tempos discutida: o fortalecimento da integração entre os setores Educação e Saúde, possibilitando a intersetorialidade defendida pelo Sistema Único de Saúde (SUS) e a corresponsabilização entre estes setores, que se acostumaram a trabalhar isoladamente, ou seja, promovendo uma articulação entre os sistemas de Educação e o de Saúde (SANTIAGO et al., 2012).

Ao que tange à formação, enquanto acadêmicos da área da Saúde, uma das estratégias para um fortalecimento curricular é a diversificação dos cenários de aprendizagem. Tal estratégia aproxima os estudantes da Saúde da realidade dos indivíduos/comunidades, permitindo um olhar mais crítico e reflexivo a respeito dos problemas cotidianos da população. Uma das opções para essa diversificação é a aprendizagem baseada na comunidade, em que os acadêmicos sejam integrados à comunidade e, assim, possam construir seu aprendizado com base em vivências mais abrangentes que aquelas desenvolvidas em estágios restritos aos ambientes dos serviços de Saúde. Essa prática integradora está presente em vivências como as descritas neste trabalho. Nelas ocorre concretamente a integração de conteúdo, sustentada pela 
ação-reflexão-ação dos atores dessa prática em um mundo real - uma construção social - que fortalece a formação dos futuros profissionais (FERREIRA; SILVA; AGUER, 2007).

\section{CONSIDERAÇÕES FINAIS}

Faz-se necessário que a discussão a respeito da temática abordada seja implementada em outras ocasiões e até mesmo de forma transversal nos conteúdos programáticos pelos docentes da instituição e demais escolas, pois percebeu-se o quanto a temática gera discussões e o interesse dos escolares em participar expondo suas opiniões. Afinal, as discussões de gênero devem permear a construção do perfil social dos sujeitos.

Percebeu-se que os escolares já possuíam concepções formuladas com base em suas vivências com relação aos Papéis de Gênero, já sabiam a respeito da temática e gostaram de falar sobre ela, pois muitos avaliaram a implementação da atividade de forma positiva e expressaram o desejo de que houvesse outras discussões; eles conseguiram ver a importância dessa temática e se mostraram dispostos a discutir e a re/pensar os conceitos que envolvem o assunto, de maneira participativa e colaborativa.

Traçou-se, como sugestão que, nos próximos períodos em que a disciplina for ofertada, seja realizado um novo dimensionamento quando se referir ao levantamento de necessidades, de modo que se tenha algum contato com a turma antes da sua implementação. A temática não deve ser passada de forma muito genérica, sem considerar as subjetividades da turma, correndose o risco de, em alguns casos, o planejado não condizer com a realidade da turma. Então, com uma observação prévia, facilitar-se-á o desenvolvimento tanto do planejamento quanto do momento final que é a implementação.

Ao se pensar-se nas dificuldades vivenciadas, cabe destaque à nossa inexperiência na docência, pois em alguns momentos não sabíamos como trazer os discentes para discussão, mas isso foi superado de forma positiva devido à característica participativa da turma e à flexibilidade em que desenvolvemos a implementação, adquirindo experiências importantes para lecionar.

Fica demonstrado que a prática docente requer um planejamento estratégico e uma articulação tanto com os condutores da implementação quanto com os discentes, para que assim a construção de conhecimentos seja efetiva. Destaca-se que a ação contribuiu de forma produtiva para desenvolvermos habilidades e competências importantes para a formação em Enfermagem. 


\section{REFERÊNCIAS}

ALVAREZ, Teresa; VIEIRA, Cristina. O papel da educação no caminho que falta percorrer em Portugal na desconstrução dos estereótipos de género: breves reflexões. Exedra, Suplemento temático Sexualidade, Género e Educação, dez. 2014, p. 8-17. Disponível em: <http://www.exedrajournal.com/wp-content/uploads/2014/12/sup14-8-17.pdf >. Acesso em: 22 maio 2017.

ALVES, Solange Reffatti; ALVES, Alexandre Oliveira; ASSIS, Michelli Cristina S. Educação popular em saúde como estratégia à adesão na realização do exame colpocitológico. Cienc. Cuid. Saúde, v. 15, n. 3, p. 570-4, 2016. Disponível em: <http://eduem.uem.br/ojs/index.php/CiencCuidSaude/article/ viewFile/27125/18085>. Acesso em: 01 jun. 2018.

AQUINO, Júlio Groppa. Diferença e preconceito na escola: alternativas teóricas e práticas. São Paulo: Summs, 1998. 215p.

BORNSTEIN, Vera Joana; MOREL, Cristina Massadar; PEREIRA, Ingrid D’avilla Freire; LOPES, Márcia Raposo. Desafios e perspectivas da Educação Popular em Saúde na constituição da práxis do Agente Comunitário de Saúde. Interface - Comunicação, Saúde, Educação, v. 18, Supl. 2, p. 1327-40, 2014. Disponível em: <https://www. scielosp.org/pdf/icse/2014.v18suppl2/1327-1339/pt>. Acesso em: 1 jun. 2018.

BRASIL, Mikael Lima; SANTOS, Laís Vasconcelos; PAZ, Larissa F. Araújo, FREITAS, Javanna L. G. da Silva; QUEIROZ, Júlio César. Saberes em Paulo Freire: educação popular em saúde na procura por uma "pedagogia da esperança" e seus entrelaços com o processo emancipatório de LGBT. Revista Rede de Cuidados em Saúde, v. 11, n. 1, p. 1-12, 2017. Disponível em: <http://publicacoes.unigranrio.com.br /index.php/rcs/article/view/4127/2355>. Acesso em: 1 jun. 2018.

BRASIL, Ministério da Saúde. Secretaria de Vigilância em Saúde. Secretaria de Atenção à Saúde. Política Nacional de Promoção da Saúde. Brasília/DF: Ministério da Saúde, 2006. Disponível em: <http://bvsms.saude.gov.br/bvs/publicacoes/politica_nacional_promocao_saude_3ed.pdf> Acesso em: jun. 2018.

CARTA DE OTTAWA. Disponível em: <http://bvsms.saude.gov.br/bvs/publicacoes/carta_ottawa.pdf $>$. Acesso em: mar.2017.

CÉSAR, Carla Patrícia H. A. R. et al. Promoção da saúde e fonoaudiologia: possibilidades de atuação. In: PARANHOS, Luis Renato; SORDI, Cláudia; CÉSAR, Carla Patrícial H. A. R. (Orgs). Coletâneas em saúde. São José dos Pinhais: Editora Plena; 2016. 4v. p. 61-70.

COSTA, Felipe dos S.; SILVA, Jorge Luiz L; DINIZ, Márcia Isabel G.. A importância da interface educaçãolsaúde no ambiente escolar como prática de promoção da saúde. Informe-se em promoção da saúde, v.4, n.2, p.30-33, 2008. Disponível em:

<http://www.uff.br/promocaodasaude/PS\% 20no\%20ambiente $\% 20$ escolar.pdf $>$. Acesso em: 01 mar. 2017.

EVANGELISTA, Solange Castro et al. Percurso das ações de promoção da saúde na residência multiprofissional: análise à luz de um referencial europeu. Tempus Actas de Saúde 
Coletiva, Brasília/ DF, v. 10, n. 4, p. 69-82, 2016. Disponível em:

$<$ http://tempusactas.unb.br/index.php/tempus/article/view/2291/1710>. Acesso em: 11 ago. 2017.

FERREIRA, Ricardo Corrêa; SILVA, Roseli Ferreira da; AGUER, Cristiane Biscaino. Formação profissional no SUS: o papel da Atenção Básica em Saúde na perspectiva docente. Revista Brasileira de Educação Médica, São Paulo/SP, v.31, n. 1, p. 52- 9, 2007. Disponível em: <http://www.scielosp.org/ pdf/rbem/v31n1/08.pdf>. Acesso em: 11 ago. 2017.

FINCO, Daniela. Relações de gênero nas brincadeiras de meninos e meninas na educação infantil. Pro-Posições. v. 14, n. 3, p. 90-101, 2003. Disponível em: <http://periodicos.sbu.unicamp.br/ojs/index.php/ proposic/article/view/8643863/11340>. Acesso em: 22 maio 2017.

GUIMARÃES, Gehisa; AERTS, Denise; CÂMARA, Sheila Gonçalves. A escola promotora da saúde e o desenvolvimento de habilidades sociais. Revista da Sociedade de Psicologia do Rio Grande do Sul, v. 12, n. 2, p. 88-95, 2012. Disponível em:

<file:///C:/Users/N\%C3\%ADvia\%20Maria/Downloads/76-304-1-PB.pdf>. Acesso em: 02 mar. 2017.

KRUSCHEWSKY, Julie Eloy; KRUSCHEWSKY, Mavie Eloy; CARDOSO, Jefferson Paixão. Experiências pedagógicas de educação popular em saúde: A pedagogia tradicional versos a problematizadora. Rev. Saúde. Com., v. 4, n. 2, p. 160-76, 2016. Disponível em: $<$ http://www.uesb. br/revista/rsc/ojs/index.php/rsc/article/view/94/442 >. Acesso em: 1 jun. 2018.

LEÃO, Andreza Marques de Castro. Estudo analítico-descritivo do curso de pedagogia da UNESP-Araraquara quanto à inserção das temáticas de sexualidade e orientação sexual na formação de seus alunos. 2009. Tese (Doutorado em Educação Escolar) - Universidade Estadual Paulista, Faculdade de Ciências e Letras, Campus de Araraquara, 2009. Disponível em: <https://repositorio.unesp.br/handle/11449/101587>. Acesso em: 22 maio 2017.

MADUREIRA, Ana Flávia do Amaral; BRANCO, Ângela Uchoa. Gênero, sexualidade e diversidade na escola a partir da perspectiva de professores/as. Temas Psicol., Ribeirão Preto, v.23, n.3, p. 577-591, 2015. Disponível em:

<http://pepsic.bvsalud.org/pdf/tp/v23n3/v23n3a05.pdf >. Acesso em: 22 maio 2017.

MELO, Brunilla Thaís Queiroz. Trabalho, Educação e Relações de Gênero: Uma análise crítica. Interface, v. 11, n. 2, 2014. Disponível em:

<http://www.ufpb.br/evento/lti/ocs/index.php/17redor/ 17redor/paper/viewFile/24/17>.

Acesso em: 22 maio 2017.

MILHOMEM, Maria Santana F. dos S. Gênero e sexualidade na escola: experiências vividas na rede municipal de Palmas, Tocantins. Caderno Espaço Feminino, v. 28, n. 1, p. 36-50, 2015. Disponível em:

<http://www.ufpb.br/evento/lti/ocs/index.php/17redor/17redor/paper/viewFile/24/17> $>$. Acesso em: 22 maio 2017.

MONT'ALVERNE, Daniela Gardano B.; CATRIB; Ana Maria F. Promoção da saúde e as escolas: como avançar. Rev. Bras. Promoc. Saúde, Fortaleza, v. 26, n. 3, p. 307-308, 2013. 
Disponível em: <file://C:/Users/N\%C3\%ADvia\%20 Maria/Downloads/2924-9043-1PB.pdf>. Acesso em: 01 mar.2017.

MONTEIRO, Estela Maria L. Meirelles. Educação popular em saúde. Recife/ PE, Ed. Universitária da UFPE, 2015. 51p.

MONTEIRO, Rosa; AGOSTINHO, Luísa; DANIEL, Fernanda. Um diagnóstico da desigualdade de gênero num município em Portugal: estruturas e representações. Rev. Adm. Pública, Rio de Janeiro, v. 49, n. 2, p. 423-46, 2015. Disponível em:

<http://www.scielo.br/pdf/rap/v49n2/0034-7612-rap-49-02-00 423.pdf>. Acesso em: 1 jun. 2018.

NEMI NETO, João. Questões de identidade(s) de gênero(s) e orientação sexual: uma abordagem através da Pedagogia Queer. Revista Espaço Acadêmico, v. 14, n. 168, p. 27-34, 2015. Disponível em: 〈file:///C:/Users/cliente2/Downloads/27365-118493-2-PB. pdf>. Acesso em: 22 maio 2017.

PRATES, Mónica; MARCHÃO; Amélia de Jesus. Estudo das conceções de género presentes num jardim-de-infância da cidade da Ponte de Sor: as conceções das crianças, das educadoras e dos/as encarregados/as de educação. Aprender Revista da Escola Superior de Educação Instituto Politécnico de Portalegre, n. 36, p. 86-100, 2015. Disponível em: $<$ https://comum.rcaap.pt/bitstream/10400.26/ 14193/1/Prates\%20\&\% 20March\%C3\%A3o,\%20Aprender,\%202015.pdf>. Acesso em: 1 jun. 2018.

PIOVESAN, Leonardo Rodrigues et al. Promoção da saúde na perspectiva de enfermeiros de atenção básica. Rev. Enferm. UERJ, Rio de Janeiro, v. 24, n. 3, p. 1-6, 2016. Disponível em: 〈http://www.e-publicacoes.uerj.br/index.php/enfermagemuerj/article/view/5816/19396 >. Acesso em: 1 jun. 2018.

RABELO, Amanda Oliveira. Contribuições dos estudos de género às investigações que enfocam a masculinidade. Ex жеquo., n. 21, p. 161-76, 2010. Disponível em: <http://www.scielo.mec.pt/pdf/aeq/ n21/n21a12.pdf $>$. Acesso em: 1 de jun. 2018.

SANTIAGO, Lindelvânia Matias et al. Implantação do Programa Saúde na Escola em Fortaleza-CE: atuação de equipe da Estratégia Saúde da Família. Rev. Bras. Enferm, Brasília v. 65, n. 6, p. 1026-1029, 2012. Disponível em:

<http://www.scielo.br/pdf/reben/v65n6/a20v65n6.pdf>. Acesso em: 01 mar. 2017.

SOUTO, Lúcia Regina Florentino; OLIVEIRA, Maria Helena. Movimento da Reforma Sanitária Brasileira: um projeto civilizatório de globalização alternativa e construção de um pensamento pós-abissal. Saúde Debate, Rio de Janeiro, v. 40, n. 108, p. 204-18, 2016. Disponível em: <https://www. scielosp.org/pdf/sdeb/2016.v40n108/204-218/pt>. Acesso em: 1 jun. 2018.

\section{SOBRE OS AUTORES}


Augusto José Bezerra de Andrade é académico do Curso de Enfermagem da Universidade do Estado do Rio Grande do Norte (UERN).

E-mail: andrade.augustojose@ hotmail.com

Erika Carla de Sousa Dias é académica do Curso de Enfermagem da Universidade do Estado do Rio Grande do Norte (UERN).

E-mail: erika.pb2013@hotmail.com

Rafael Tavares Silveira Silva é enfermeiro graduado pela Universidade Federal do Rio Grande do Norte (UFRN), Mestre pelo Programa de Pós-Graduação em Enfermagem da UFRN e exerce a docência na Universidade do Estado do Rio Grande do Norte (UERN).

E-mail: rtssrafa@yahoo.com.br

Ellany Gurgel Cosme do Nascimento é Doutora em Ciências da Saúde pela Universidade Federal do Rio Grande do Norte (UFRN) e Professora Adjunta III da Universidade do Estado do Rio Grande do Norte (UERN).

E-mail: ellanygurgel@hotmail.com 